\title{
Lignocellulose biodegradation: Fundamentals and applications
}

\author{
S. Malherbe \& T.E. Cloete
}

\section{Introduction}

Natural pastures are one of South Africa's most important agricultural resources for it provides the cheapest source of animal feed (Aucamp \& Danckwerts 1989). Natural grazing is threatened by expansion of the Karoo (semi-desert region) into grasslands, overgrazing, poisonous plants, poor grazing management practices, and bush densification. Finally, expanding human activities (agriculture, housing, and industrialization) places a demand on already overburdened natural grazing resources. Therefore, the use and re-use of lignocellulosic wastes for animal feed will become a South African reality in the near future. Sadly, much lignocellulose waste is often disposed of by biomass burning, which is not restricted to underdeveloped countries alone, but is considered a global phenomenon (Levine 1996). This scenario does not only apply to South Africa alone, for some or all of the listed problems are common in many parts of the world today.

The problem of increasing the utility of lignocellulose wastes has been known for decades. In addition to the growing demand for traditional applications (paper manufacture, biomass fuels, composting, animal feed, etc.), novel markets for lignocellulosics have been identified in recent years. The intensity of research and the magnitude of capital investment in this field increased vastly once commercial viability seemed probable for many of these new applications. The most ambitious of these has been the conversion of lignocellulose to alternative energy carriers (e.g. fuel ethanol, acetone and butanol) (Kaylen et al. 2000; Lee 1997; Mitchell 1998; Wheals et al. 1999). The pulp and paper industry discovered lignocellulose biotechnology could improve process efficiency through savings in money and energy (Breen \& Singleton 1999; Scott et al. 1998). Others aimed at improving digestibility of nutritionally poor forages by exposing these lignocellulosics to white-rot fungi (Agosin \& Odier 1985; Karunanandaa et al. 1992).

The complete and successful utilization of lignocellulose by man remains a daunting task, whatever the intended application. Defeating the barriers, which prevent commercial exploitation of lignocellulose, will be the key to its successful application in biotechnological endeavors. This review will not focus on current or new chemical and physical lignocellulose processing technologies (and their problems). Rather, the aim is to summarize the current knowledge available on lignocellulose biodegradation, and add value to that knowledge by discussing ways to integrate natural processes into low cost, low technology biotechnological applications.

\section{Lignocellulose composition}

\subsection{Chemical composition}

The chemical composition of plants differs considerably and is influenced by genetic and environmental factors (Table 1). Cellulose, hemicellulose, and lignin are the main constituents of lignocellulosic materials (Deobald \& Crawford 1997). Apart from these primary polymers, plants comprise other structural polymers (e.g. waxes, proteins). Cellulose is a linear polymer of glucose linked through $\alpha$-1,4-linkages and is usually arranged in microcrystalline structures, which is very difficult to dissolve or hydrolyse under natural conditions. The degree of polymerization (DP) of cellulose chains range from 500 to 25000 (Kuhad et al. 1997; Leschine 1995). Hemicellulose is a heteropolysaccharide composed of different hexoses, pentoses, and glucoronic acid. Hemicellulose is more soluble than cellulose and is frequently branched with DP of 100 to 200 (Kuhad et al. 1997). Xylan is the most common hemicellulose component of grass and wood. Lignin is a highly irregular and insoluble polymer consisting of phenylpropanoid subunits, namely $p$-hydroxyphenyl (H-type), guaiacyl (G-type),

Table 1. Typical chemical composition of various lignocellulosic materials (Betts et al. 1991)

\begin{tabular}{lccc}
\hline Raw material & Lignin (\%) & Cellulose (\%) & Hemicellulose (\%) \\
\hline Hardwoods & $18-25$ & $45-55$ & $24-40$ \\
Softwoods & $25-35$ & $45-50$ & $25-35$ \\
Grasses & $10-30$ & $25-40$ & $25-50$ \\
\hline
\end{tabular}


and syringyl (S-type) units. Unlike cellulose or hemicellulose, no chains containing repeating subunits are present, thereby making the enzymatic hydrolysis of this polymer extremely difficult.

\subsection{Tertiary architecture}

The tertiary architecture of lignocellulose structures is directed by a variety of covalent and non-covalent linkages between the various constituents. Cellulose is complexed with hemicellulose, lignin, and other components, which complicate their hydrolysis - hence the comparison with reinforced concrete (Leonowicz et al. 1999; Tomme et al. 1995). Cellulose microfibrils are stabilized by intra- and intermolecular hydrogen bonds and surrounded by hemicellulosic polysaccharides (mannans and xylans) linked to cellulose by covalent and hydrogen bonds (Heredia et al. 1995). These covalent bonds are extremely resistant to chemical and biological hydrolysis. On the other hand, amorphous regions within the cellulose crystalline structure have a heterogeneous composition characterized by a variety of different bonds. Ultimately, this asymmetrical arrangement, which characterizes amorphous regions, is crucial to the biodegradation of cellulose and will be discussed later in the manuscript. The accessibility of cell wall polysaccharides from the plant to microbial enzymes is dictated by the degree to which they are associated with phenolic polymers (Chesson 1981; Kuhad et al. 1997). In grasses, ferulic and $p$ coumaric acids are esterified to hemicellulose and lignin (Jeffries 1990; Mueller-Harvey \& Hartley 1986). Xylans appear to be a major interface between lignin and other carbohydrate components (Cornu et al. 1994; Jeffries 1990). Ferulic acid anchors hydrophobic lignins to hydrophilic polysaccharides via alkali-sensitive ester bonds. Intramolecular lignin bonds are usually of the alkali-resistant ether type. This intricate association with lignin shields hemicellulose from direct enzymatic hydrolysis (Sun et al. 1996).

\section{Lignocellulose biodegradation}

Lignocellulose is a complex substrate and its biodegradation is not dependent on environmental conditions alone, but also the degradative capacity of the microbial population (Waldrop et al. 2000). The composition of the microbial community charged with lignocellulose biodegradation determines the rate and extent thereof.

\subsection{Cellulose and hemicellulose}

The efficient hydrolysis of cellulose requires the concerted action of at least three enzymes: (1) endo-glucanases to randomly cleave intermonomer bonds; (2) exoglucanases to remove mono- and dimers from the end of the glucose chain; and (3) $\beta$-glucosidase to hydrolyze glucose dimers (Figure 1) (Deobald \& Crawford 1997; Tomme et al. 1995).

The concerted actions of these enzymes are required for complete hydrolysis and utilization of cellulose. The rate-limiting step is the ability of endo-glucanases to reach amorphous regions within the crystalline matrix and create new chain ends, which exo-cellobiohydrolases can attack.

Although similar types of enzymes are required for hemicellulose hydrolysis, more enzymes are required for its complete degradation because of its greater complexity compared to cellulose. Of these, xylanase is the best studied (reviewed by Kuhad et al. 1997).

Although the model described in Figure 1 was developed from data obtained from Trichoderma koningii and Phanerochaete chrysosporium, it does well to describe the general aspects of enzymatic hydrolysis of cellulose (reviewed by Tomme et al. 1995). However, a fundamental difference exists in the mechanism of cellulose hydrolysis between aerobic and anaerobic fungi and bacteria (reviewed by Leschine 1995; Tomme et al. 1995). Aerobic fungi and bacteria characteristically comprise non-complexed cellulase systems, which entail the secretion of the cellulose hydrolysis enzymes into the culture medium. However, anaerobic bacteria (especially Clostridium spp.) and fungi (of the genera Neocallimastix, Piromonas and Sphaeromonas) contain complexed cellulase systems where the cellulose hydrolyzing enzymes are contained in membrane-bound enzyme complexes (called cellulosomes). This fundamental difference has profound implications for biotechnology applications. Biotechnological applications based on anaerobic fungi and bacteria might have an advantage over aerobic systems in terms on hydrolysis efficiency. Complexed cellulase systems allow greater coordination between the different cellulose hydrolyzing enzymes. Their close association will restrict loss of degradation intermediates due to dynamic environmental conditions. In aerobic systems, where active aeration and agitation is required, loss of the secreted enzymes and their degradation intermediates might prove detrimental to overall process efficiency. This apparent contradiction might be offset when the energetics of aerobic and anaerobic microorganisms is compared. In general, aerobic microorganisms gain far more energy from glucose than anaerobic micro-organisms (38 mole ATP vs. 2-4 mole ATP per mole of glucose). Therefore, the apparently "aggressive" cellulose hydrolyzing strategy utilized by aerobes might be beneficial given the potential enormous gain in metabolic energy. However, given the low technical requirements of anaerobic applications as compared to aerobic systems (absence of vigorous agitation to facilitate aeration and flow control technologies), the use of anaerobic fungi and bacteria for use in low cost bioremediation projects might be more attractive given their highly 
efficient cellulose hydrolysis machinery.

\subsection{Lignin}

Lignin degradation by white-rot fungi is an oxidative process and phenol oxidases are the key enzymes (Kuhad et al. 1997; Leonowicz et al. 1999). Of these, lignin peroxidases (LiP), manganese peroxidases (MnP) and laccases from especially white rot fungi ( $P$. chrysosporium, Pleurotus ostreatus and Trametes versicolor) have been best studied. LiP and MnP oxidize the substrate by two consecutive one-electron oxidation steps with intermediate cation radical formation. Laccase has broad substrate specificity and oxidises phenols and lignin substructures with the formation of oxygen radicals. Other enzymes that participate in the lignin degradation processes are $\mathrm{H}_{2} \mathrm{O}_{2}$-producing enzymes and oxido-reductases, which can be located either intra- or extracellularly.

Bacterial and fungal feruloyl and $p$-coumaroyl esterases are relatively novel enzymes capable of releasing feruloyl and $p$-coumaroyl and play an important role in biodegradation of recalcitrant cell walls in grasses (Kuhad et al. 1997). These enzymes act synergistically with xylanases to disrupt the hemicellulose-lignin association, without mineralization of the lignin per se (Borneman et al. 1990;

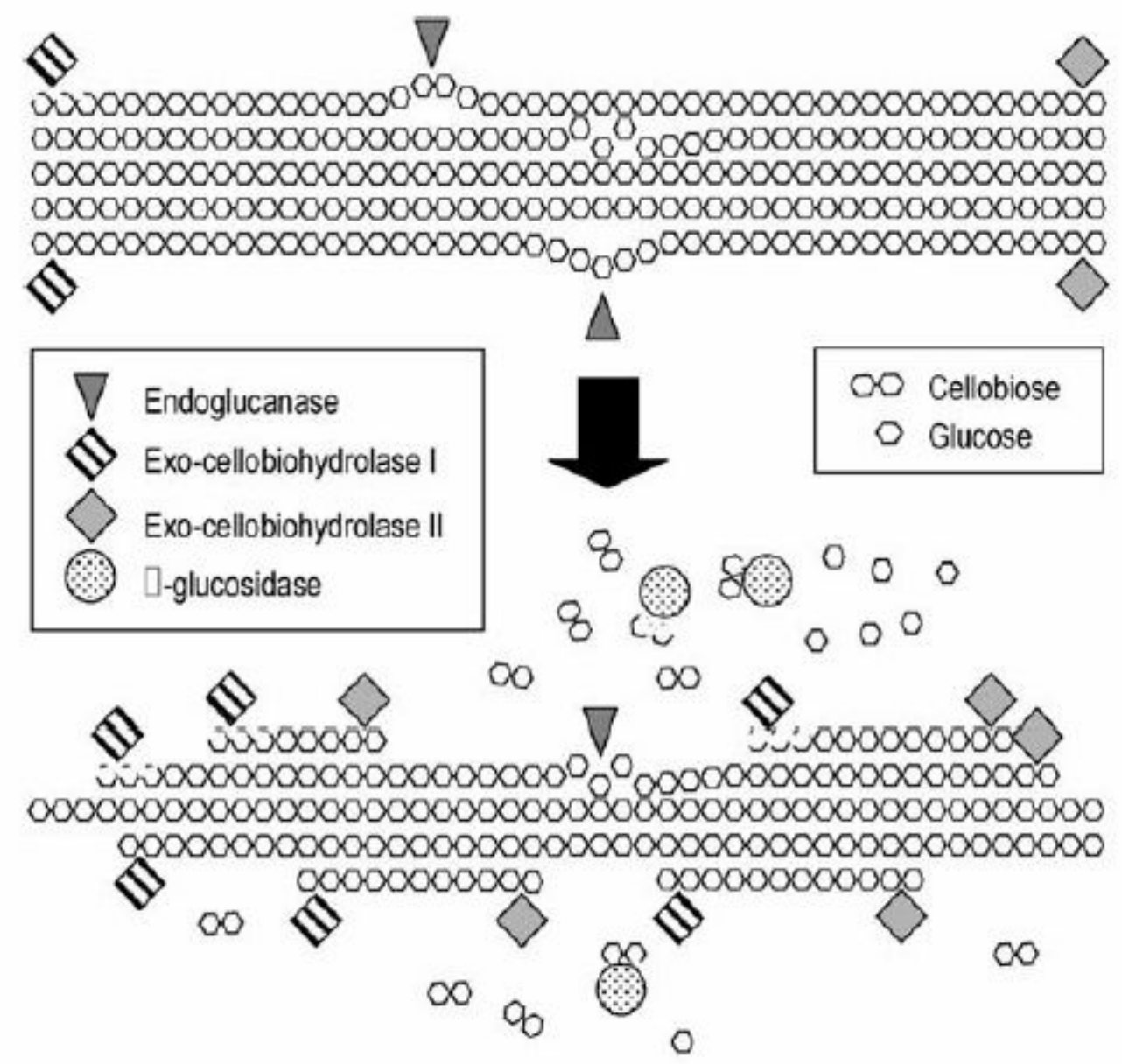

Figure 1. A simplified schematic representation of the process involved in complete enzymatic hydrolysis of a cellulose microfibril. Endoglu-cases attack amorphous regions within the crystalline microstructure, thereby creating new foci for attack by exo-cellobiohydrolases. Cellobiose dimers are cleaved by $\beta$-glucosidases to yield glucose monomers, which can now be transported across the membrane to participate in energy generating metabolic reactions

Fillingham et al. 1999; Tuor et al. 1995). Therefore, hemicellulose degradation is required before efficient lignin removal can commence.

\subsection{Ecology of lignocellulose biodegradation}

Lignocellulose degradation is essentially a race between cellulose and lignin degradation (Reid 1989). This contest is even more extensive and complex in nature (Rayner \& Boddy 1988). Decomposition curves for complex substrates incubated in soil, such as plant residues, usually yield a multislope decomposition curve (Table 2) (Paul 
\& Clark 1989; Van Veen et al. 1984).

Fungi with restricted metabolic capabilities (e.g. soft rots like Mucor spp.) develop mutualistic relationships with and thrive alongside fungi degrading cellulose and lignin. Microorganisms unable to overcome the lignin or physical barrier can obtain energy from the low molecular weight intermediates released from lignocellulose by the true white-rot fungi. Such complex associations have been observed under natural conditions (Blanchette et al. 1978).

Table 2. Different rates of degradation of the various components of straw lignocellulose incubated in soil (Paul \& Clark 1989; Van Veen et al. 1984). Although the cellulose and hemicellulose fraction cannot be clearly distinguished from this example, it does indicate that lignin and the humic fraction of the soil organic matter is highly resistant to biodegradation

\begin{tabular}{llll}
\hline Organic matter pool & \multicolumn{1}{c}{$\begin{array}{c}\text { Decomposition rate } \\
k \text { (per days) }\end{array}$} & $\begin{array}{c}\text { Utilization } \\
\text { efficiency (\%) }\end{array}$ \\
\hline Decomposable microbial products & 0.8 & 40 & \\
Recalcitrant plant and microbial & 0.325 & & \\
$\quad$ products & & 60 \\
Easily decomposable organic matter & 0.2 & 40 \\
Slowly decomposable organic matter & 0.08 & 10 \\
Lignin & 0.01 & 20 \\
Active protected soil organic matter & $3 \times 10^{-4}$ & 20 \\
Old organic matter & $8 \times 10^{-8}$ & & \\
\hline
\end{tabular}

\subsubsection{Actinomycetes and bacteria}

Lignocellulose biodegradation by prokaryotes is essentially a slow process characterized by the lack of powerful lignocellulose degrading enzymes, especially lignin peroxidases. Grasses are more susceptible to actinomycete attack than wood (Antai \& Crawford 1981; McCarthy 1987). Together with bacteria, actinomycetes play a significant role in the humification processes associated with soils and composts (Trigo \& Ball 1994). The enzymatic ability to cleave alkyl-aryl ether bonds enable bacteria to degrade oligomeric and monomeric aromatic compounds released during fungal lignin degradation (Vicuna et al. 1993; Vicuna 2000; White et al. 1996).

Therefore, lignocellulose biodegradation by prokaryotes is of ecological significance, but lignin biodegradation by fungi, especially white-rot fungi, is of commercial importance.

\subsubsection{Fungi}

Most fungi are capable cellulose degraders. However, their ability to facilitate rapid lignocellulose degradation attracted attention from scientists and entrepreneurs alike. White-rot fungi comprise powerful lignin degrading enzymes that enable them in nature to bridge the lignin barrier and, hence, overcome the rate-limiting step in the carbon cycle (Elder \& Kelly 1994). Of these, Phanerochaete chrysosporium is the best studied. New information regarding the identities of the cellulose, hemicellulose or lignin degrading enzymes, their unique catalytic capabilities, the physiological conditions required for optimum secretion or activity etc. is constantly being added to an already impressive volume of work and varies between fungi and bacterial genera, species and even strains.

Anaerobic fungi (Piromyces spp., Neocalli-mastix spp. and Orpinomyces spp.) form part of the rumen microflora. These fungi produce active polymer degrading enzymes, including cellulases and xylanases (Hodrova et al. 1998). Their cellulases are among the most active reported to date and able to solubilise both amorphous and crystalline cellulose (Wubah et al. 1993). These fungi can be used in situations where process principles and design necessitate anaerobic conditions. In such a scenario, ruminant manure will serve as inoculum and this waste product will meet a crucial requirement in biotechnology - cost effectivity versus optimum utility. 


\section{Barriers to lignocellulose biodegradation}

\subsection{Microorganism access to substrate}

The physical barrier concept is best described by making use of the rumen as an example. The rumen being an anaerobic environment, and having discussed the distinctiveness of cellulose degrading systems under anaerobic conditions in section 3.1, it is clear that access and attachment of the microorganism to the substrate is vital if efficient cellulose hydrolysis is to be effected. The waxes and cuticle of an intact epidermis prevent microorganisms access to the interior of leaves and stems (Wilson \& Mertens 1995). The ruminant circumvents the physical barrier effect imposed by the lignocellulose higher-order structure by physically reducing the particle size of the plant materials during ingestion. Anaerobic fungi alleviate the physical barrier effect further by physically disrupting lignified tissues, allowing microorganisms greater access to the digestible portions of the plant fiber (Varga \& Kolver 1997). According to Wilson and Mertens (1995) degradation of the middle lamella-primary wall region by rumen bacteria is not only prevented by the chemical nature (lignin concentration) but also by physical structure and architecture.

Therefore, in order for man to successfully exploit lignocellulosics for commercial purposes, treatments that increase the accessibility of the catalyst (whether microbial or enzymic) to the substrate have been studied (Fan et al. 1982). These include mechanical, chemical, thermal, and biological pretreatments. Again, the principles of cost and profit govern the choice of method to be used. Usually, choices are not only influenced by available funds and time, but also by the value of the end-product, which may warrant the use of a more expensive procedure. Certainly for bioremediation purposes, practical issues relating to the type of substrate available (e.g. grasses vs. wood), cost of on-site pretreatment (transport to and installation of equipment on-site), etc. will impact the budget of the project.

\subsection{Enzyme access to substrate}

As discussed in section 3, aerobic fungi and bacteria secrete cellulose and hemicellulose hydrolyzing enzymes into the culture medium. Evidence also suggest the same situation applies to most lignin degrading enzymes. Therefore, unlike anaerobic microorganisms, direct physical contact of the enzyme delivery agent with the substrate is not essential to facilitate polymer hydrolysis. However, it is at the lower order level structures (tertiary and secondary) of the substrate that enzyme preclusion can occur.

Polymer hydrolysis can be complicated by various substrate and enzymatic factors. Crystalline cellulose is highly recalcitrant, yet it is completely hydrolysable through the concerted action of all endo- and exo-acting enzymes (see section 3.1). However, endo-and exoglucanases are inhibited by cellobiose and the presence or absence of cellobiase is the rate-limiting step. Lignin on the other hand contains no chains of repeating subunits, thereby making the enzymatic hydrolysis of this polymer extremely difficult.

Despite the above-mentioned complications associated with enzymatic polymer hydrolysis, the primary problem remains the tertiary architecture of the lignocellulose complex. Lignin-carbohydrate complexes (LCCs) are recognized as key structures determining forage digestibility (Hatfield et al. 1999). These intricate associations between cellulose, hemicellulose and lignin prevent polymer hydrolyzing enzymes access to its substrates (Cornu et al. 1994).

According to Tomme et al. (1995) and Grethlein (1985) the accessibility of enzymes to wood and fibers is limited by factors such as adsorption to surface areas, low fiber porosity, and low median pore size of fibers. Reid (1995) suggested that physical contact between enzyme and substrate is the rate-limiting step in lignin degradation. Grethlein (1985) indicated that substrate pretreatment (using dilute sulphuric acid in this example) is necessary to increase the number of available sites for cellulase action.

The factors discussed in this section will have a profound impact on the outcome of biotechnological applications. Again, the project budget and the value of the end-product will determine the degree of capital investment required to improve access of polymer hydrolyzing enzymes to the substrate. Low-cost and lowtechnology bioremediation projects are likely to suffer from this dilemma because it represents an engineering challenge as well. Improving access of microorganisms to the substrate by substrate pretreatment alone might not be sufficient. Lignocellulosic substrates with small pore volumes not only deny biological catalysts complete access to the substrate, but it incurs hydraulic problems as well. This dilemma presents itself as a target for future research initiatives. Alternatively, if the substrate quality cannot be improved then the desired substrate must be defined by means of a thorough lignocellulose screening procedure and procured if available.

\subsection{Toxicity of lignin-carbohydrate complexes and lignocellulose degradation intermediates}

Careful consideration must be made regarding the choice of the lignocellulose material to be incorporated into the biotechnology process. Toxic substances released from plant cells during the process might result in catalyst inhibition or decay followed by process failure. Intrinsic substrate toxicity has been linked to inhibition of whiterot fungi (Wolfaardt et al. 1999).

Toxicity of lignin-carbohydrate complexes (LCCs) to rumen microflora has been debated, but in vivo toxicity 
is thought to be insignificant due to dilution and rapid detoxification by the microflora (Cornu et al. 1994; Wilson \& Mertens 1995). However, the toxic effects of LCCs at biodegradation foci remain largely unknown.

Due to its polyphenolic composition, aromatic lignin degradation intermediates are formed during lignocellulose degradation. These then enter a variety of natural and man-made environments. Free phenolic acids and aldehydes have been detected in wheat straw extracts (Galletti et al. 1990; Milstein et al. 1981; Vered et al. 1981). The degradation of lignin by white-rot fungi in particular releases intermediates that may enter anaerobic environments. Lignin degradation is very slow under anaerobic conditions and, depending on pressure and time scale, leads to the accumulation of humus to form peat, organic soil matter, lignite, and coal (Heider \& Fuchs 1997). Although polymeric lignin remains stable in anaerobic environments for long periods of time, bacterial consortia actively metabolise smaller degradation products (Egland et al. 1997; Elder \& Kelly 1994).

This review will not focus on the potential toxicity of intermediate and end-products that are produced during the chemical and physical pretreatment of lignocellulose materials. For this purpose, the reader is referred to an excellent review on that specific subject (Palmqvist \& Hahn-Hägerdal 2000).

\section{Biotechnological application of lignocellulose and its biodegradation}

The primary objective of lignocellulose pretreatment by the various industries is to access the potential of the cellulose and hemicellulose encrusted by lignin within the lignocellulose matrix. The combination of solid-state fermentation (SSF) technology with the ability of white-rot fungi to selectively degrade lignin has made possible

Table 3. The effect of time on composition of effluent obtained from ensiled Italian ryegrass (McDonald 1981)

\begin{tabular}{cccccccc}
\hline & & \multicolumn{7}{c}{ Components of effluent $(\mathrm{g} / \mathrm{kg})$} \\
\cline { 3 - 8 } Day & $\mathrm{pH}$ & $\mathrm{DM}$ & Total-N & $\mathrm{NH}_{3}-\mathrm{N}$ & $\begin{array}{c}\text { Acetic } \\
\text { acid }\end{array}$ & WSC & Ash \\
\hline 3 & 4.4 & 52.7 & 1.87 & 0.12 & 1.01 & 13.4 & 15.6 \\
5 & 4.2 & 64.4 & 2.91 & 0.21 & 1.50 & 8.2 & 16.4 \\
18 & 4.0 & 75.6 & 3.68 & 0.33 & 2.75 & 7.1 & 16.9 \\
32 & 4.1 & 82.2 & 4.04 & 0.40 & 3.68 & 4.6 & 18.3 \\
63 & 3.8 & 89.0 & 4.45 & 0.51 & 4.67 & 3.3 & 18.6 \\
\hline DM = dry matter & & & & & &
\end{tabular}

industrial-scale implementation of lignocellulose-based biotechnologies. The advantages and disadvantages of SSF have received attention by Mudgett (1986). SSF offers the advantages of a robust technology and outperforms conventional fermentation technologies with respect to simplicity, cost effectiveness, and maintenance requirements. These advantages make SSF an attractive technology for environmental problems where money and expertise are limited. Problems commonly associated with SSF are heat build-up, bacterial contamination, scale-up, biomass growth estimation, and control of substrate moisture content (Lonsane et al. 1985). At this stage, engineering aspects come into play and the success of scale-up will depend on bioreactor design and operation (Lonsane et al. 1992).

\subsection{Lignocellulose-based technologies using unsterile substrates}

Silage manufacture is a good example of a working technology based on unsterile lignocellulose substrates. Silage is the material produced by the controlled fermentation of moist plant material (McDonald 1981). Water authorities consider silage effluent a serious threat to natural water supplies (Haigh 1994). From the farmer's perspective, silage effluent constitutes a loss of valuable nutrients (Table 3) (McDonald 1981).

Arnold et al. (2000) used Candida utilis and Galactomyces geotrichum to reduce the polluting potential of silage effluent with an initial chemical oxygen demand (COD) of $80000 \mathrm{mg} / \mathrm{l}$. COD, phosphate and ammonia concentrations were reduced by $74-95 \%, 82-99 \%$ and $16-64 \%$ respectively. A similar effluent is produced during oyster mushroom cultivation (personal observation). These effluents represent sources of carbon and nutrients and might even in future serve as cheap sources of fermentation adjuvants.

\subsection{Biopulping}

Lignin becomes problematic to cellulose-based wood processing, because it must be separated from cellulose at enormous energy, chemical and environmental expense. Biopulping is therefore a solid-state fermentation process during which wood chips are treated with white-rot fungi to improve the delignification process. Biological 
pulping has the potential to reduce energy costs and environmental impact relative to traditional pulping operations (Breen \& Singleton 1999). The benefits of biopulping was demonstrated by Scott et al. (1998) using 40-ton scale experiments: tensile, tear and burst indexes of the resulting paper were improved (indicative of higher degree of cellulose conservation during pulping process); brightness of the pulp was increased (indicating improved lignin removal); and improved energy savings of 30-38\%.

Problems endemic to SSF still plague this concept. Inoculation, aeration and heat removal are key parameters that influence fungal activity. Also, poor colonization of wood chips by white-rot fungi has been attributed to competition with naturally occurring microorganisms or to inhibition by wood chemical components (Wolfaardt et al. 1999). Substrate sterilization is usually a major expense, and secondary contamination by airborne microorganisms must be prevented at additional costs as well. Breen and Singleton (1999) summarized decades of dissatisfaction associated with high capital costs to make SSF viable for the pulp and paper industry: "Overcoming these challenges will determine, in a large part, if biopulping becomes a reality."

\subsection{Animal feed}

Cellulose is the most important source of carbon and energy in a ruminant's diet, although the animal itself does not produce cellulose-hydrolyzing enzymes (Czerkowski 1986). Rumen microorganisms utilize cellulose and other plant carbohydrates as their source of carbon and energy. Thus, the microorganisms convert the carbohydrates in large amounts of acetic, propionic and butyric acids, which the higher animal can use as its energy and carbon sources (Colberg 1988).

The concept of preferential delignification of lignocellulose materials by white-rot fungi has been applied to increase the nutritional value of forages (Agosin et al. 1985; Akin et al. 1995; Chen et al. 1995; Zadrazil \& Isikhuemhen 1997). This increased digestibility provides organic carbon that can be fermented to organic acids in an anaerobic environment, such as the rumen.

However, upgrading of animal feed by white-rot fungi failed to reach industrial proportions. A possible explanation can be that the animals' instincts prevent them from ingesting mushrooms, for they can contain toxicants or they can be toxic to their rumen microflora and, hence, toxic to the animal also.

\subsection{Applications of genetic engineering}

The scope of lignocellulose-based applications is expanding rapidly towards applications of genetic engineering. Recently, repression of lignin biosynthesis was achieved in Populus tremuloides resulting in cellulose accumulation and healthy growth of such transgenic trees (Hu et al. 1999). Cellulose and lignocellulose fibers can be chemically modified to render it useful to miscellaneous applications in the textile industry (Ghosh \& Gangopadhyay 2000). Lignocellulose degrading actinomycetes have been used as biocontrol agents to preserve golf green turf-grass (Chamberlain \& Crawford 2000). Currently, metabolic engineering is being applied to facilitate simultaneous fermentation of hexoses and pentoses to ethanol (Aristidou \& Penttilä 2000). The future might see the application of genetically engineered microorganisms (containing lignocellulases) to biotechnological applications where lignocellulosic wastes serve as the on-site carbon and nutrient source. Commercial byproducts of lignocellulose conversion to fuel ethanol has found application as absorbents of organic pollutants and as enterosorbents (Dizhbite et al. 1999). Therefore, commercializing lignin waste production can offset process costs.

Lignocellulose is also of potential medical value. Apart from being essential in the human diet as fiber, lignocellulose can be a source of compounds with biological activity. Such compounds have potential as stimulators of the human immune system and as antiviral agents (Kiyohara et al. 2000; Sakagami et al. 1999).

\subsection{Potential of lignocellulose in space exploration}

Advances in lignocellulose research will enable scientists to contribute to space science/exploration. Space travel will benefit from this research, in the near future as the transport of lignocellulose to space can result in substantial cost savings. Lignocelluloses can be a feedstock to provide for all basic needs: fuel, energy, feedstock chemicals, food, and water. Recycling of inedible plant material by white-rot fungi (Pleurotus ostreatus) has been investigated in a Closed Ecological Life Support System (CELSS) (Sarikaya \& Ladish 1997). Incineration technology have been proposed as another way of recycling the elemental resources found in spent lignocelluloses to support agriculture in a CELSS (Wignarajah et al. 2000). Lignocellulose can therefore be the "super fuel" of the future - being a compact natural polymer containing enough potential energy to sustain man and machine in space.

\section{Conclusions}

This review aims to empower scientists with the vision to apply science to lignocellulose wastes taken for granted. 
Natural biodegradation processes and the consortia involved (e.g. rumen, termite hindgut, etc.) are treasure troves filled with the potential for lateral applications of scientific discoveries. Current working lignocellulose-based technologies produce potential polluting effluents, but when properly managed, these can overcome financial barriers preventing the success of innovative processes. The ultimate beneficiaries of this approach will be the local and national economies of communities - and the people themselves.

\section{Acknowledgements}

The authors wish to thank Pulles Howard and De Lange Inc. for sponsoring this work. We also appreciate the support from the South African Department of Arts, Culture, Science and Technology under the auspices of the Innovation Fund.

\section{References}

Agosin E \& Odier E (1985) Solid-state fermentation, lignin degradation and resulting digestibility of wheat straw fermented by selected whiterot fungi, Appl. Microbiol. Biotechnol. 21:397-403

Akin DE, Rigsby LL, Sethuraman A, Morrison III WH, Gamble GR \& Eriksson KEL (1995) Alterations in structure, chemistry, and biodegradability of grass lignocellulose treated with the white rot fungi Ceriporiopsis subvermispora and Cyathus stercoreus. Appl. Environ. Microbiol. 61: 1591-1598

Antai SP \& Crawford DL (1981) Degradation of softwood, hardwood, and grass lignocelluloses by two Streptomyces strains. Appl. Environ. Microbiol. 42: 378-380

Aristidou A \& Penttilä M (2000) Metabolic engineering applications to renewable resource utilization. Curr. Opin. Biotechnol. 11: 187-198

Arnold JL, Knapp JS \& Johnson CL (2000) The use of yeasts to reduce the polluting potential of silage effluent. Wat. Res. 34: 3699-3708

Aucamp A, Danckwerts JE (1989) Grazing Management: A Strategy for the Future. Introduction' National Department of Agriculture, Pretoria, South Africa

Betts WB, Dart RK, Ball AS \& Pedlar SL (1991) Biosynthesis and structure of lignocellulose. In: Betts WB (Ed) Biodegradation: Natural and Synthetic Materials (pp 139-155). Springer-Verlag, Berlin, Germany

Blanchette RA, Shaw CG \& Cohen AL (1978) A SEM study of the effects of bacteria and yeasts on wood decay by brown- and white-rot fungi. Scan. Elec. Micros. 2: 61-68

Borneman WS, Hartley RD, Morrison WH, Akin DE \& Ljungdahl LG (1990) Feruloyl and p-coumaroyl esterase from anaerobic fungi in relation to plant cell wall degradation. Appl. Microbiol. Biotechnol. 33: 345-351

Breen A \& Singleton FL (1999) Fungi in lignocellulose breakdown and biopulping. Curr. Opin. Biotechnol. 10: 252-258

Chamberlain K \& Crawford DL (2000) Thatch biodegradation and antifungal activities of two lignocellulolytic Streptomyces strains in laboratory cultures and in golf green turfgrass. Can. J. Microbiol. 46: 550-558

Chen J, Fales SL, Varga GA \& Royse DJ (1995) Biodegradation of cell wall components of maize stover colonized by white-rot fungi and resulting impact on in-vitro digestibility. J. Sci. Food Agric. 68: 91-98

Chesson A (1981) Effects of sodium hydroxide on cereal straws in relation to the enhanced degradation of structural polysac-charides by rumen microorganisms. J. Sci. Food Agric. 32: 745-758

Colberg PJ (1988) Anaerobic microbial degradation of cellulose, lignin, oligolignols, and monoaromatic lignin derivatives. In: Zehnder AJB (Ed) Biology of Anaerobic Microorganisms (pp 333-372). John Wiley \& Sons, New York USA

Cornu A, Besle JM, Mosoni P \& Grent E (1994) Lignin-carbohydrate complexes in forages: Structure and consequences in the ruminal degradation of cell-wall carbohydrates. Reprod. Nutr. Dev. 24: 385-398

Czerkowski JW (1986) An Introduction to Rumen Studies. Pergamon Press, Oxford, UK, pp 9-10

Deobald LA \& Crawford DL (1997) Lignocellulose biodegradation. In: Hurst CJ, Knudsen GR, Stetzenbach LD \& Walter MV (Eds) Manual of Environmental Microbiology (pp 730-737). ASM Press, Washington DC, USA

Dizhbite T, Zakis G, Kizimia A, Lazareva E, Rossinskaya G, Jurk-jane V, Telysheva G \& Viesturs U (1999) Lignin - a useful bio-resource for the production of sorption-active materials. Biores. Technol. 67: 221-228

Egland PG, Pelletier DA, Dispensa M, Gibson J \& Harwood CS (1997) A cluster of bacterial genes for anaerobic benzene ring biodegradation. Proc. Natl. Acad. Sci. USA 94: 6484- 6489

Elder DJ \& Kelly DJ (1994) The bacterial degradation of benzoic acid and benzenoid compounds under anaerobic conditions: Unifying trends and new perspectives. FEMS Microbiol. Rev. 13: 441-468

Fan LT, Lee YH \& Gharpuray MM (1982) The nature of lignocellulosics and their pretreatments for enzymatic hydrolysis. Adv. Biochem. Eng. 23: $157-187$

Fillingham IJ, Kroon PA, Willaimson G, Gilbert HJ \& Hazlewood GP (1999) A modular cinnamoyl ester hydrolase from the anaerobic fungus Piromyces equi acts synergistically with xylanase and is part of a multiprotein cellulose-binding cellulase-hemicellulase complex. Biochem. J. 343: 215-224

Galletti GC, Piccaglia R \& Concialini V (1990) Optimization of electrochemical detection in the high-performance liquid chromatography of lignin phenolics from lignocellulosic byproducts. J. Chromatogr. 507: 439-450

Ghosh P \& Gangopadyay R (2000) Photofunctionalization of cellulose and lignocellulose fibers using photoactive organic acids. Eur. Polymer J. 36: 625-634

Grethlein HE (1985) The effect of pore size distribution on the rate of enzymatic hydrolysis of cellulosic substrates. Bio/Technol. 3: 155-160

Haigh PM (1994) A review of agronomic factors influencing grass silage effluent production in England and Wales. J. Agric. Engng. Res. 57: 73-87

Hatfield RD, Ralph J \& Grabber JH (1999) Cell wall structural foundations: Molecular basis for improving forage digestibilities. Crop Sci. 39: $27-37$

Heider J \& Fuchs G (1996) Anaerobic metabolism of aromatic compounds. Eur. J. Biochem. 243: 577-596

Heredia A, Jimenez A \& Guillen R (1995) Composition of plant cell walls. Z. Lebensm. Unters. Forsch. 200: 24-31

Hodrova B, Kopecny J \& Kas J (1998) Cellulolytic enzymes of rumen anaerobic fungi Orpinomyces joyonii and Caecomyces communis. Res. Microbiol. 149: 417-427

Hu WJ, Harding SA, Lung J Popko JL, Ralph J, Stokke DD, Tsai CJ \& Chiang VL (1999) Repression of lignin biosynthesis promotes cellulose accumulation and growth in transgenic trees. Nature Biotechnol. 17: 808-812

Jeffries TW (1990) Biodegradation of lignin-carbohydrate complexes. Biodegradation 1: 163-176

Karunanandaa K, Fales SL, Varga GA \& Royse DJ (1992) Chemical composition and biodegradability of crop residues colonized by white-rot 
fungi. J. Sci. Food. Agric. 60: 105-112

Kaylen M, Van Dyne DL, Choi YS \& Blasé M (2000) Economic feasibility of producing ethanol from lignocellulosic feedstocks. Biores. Technol. 72: 19-32

Kiyohara H, Matsumoto T \& Yamada H (2000) Lignin-carbohydrate complexes: Intestinal immune system modulating ingredients in kampo (Japanese herbal) medicine, juzen-taiho-to. Planta Med. 66: 20-24

Kuhad RC, Singh A \& Eriksson KEL (1997) Microorganisms and enzymes involved in the degradation of plant fiber cell walls. Adv. Biochem. Eng. Biotechnol. 57: 45-125

Lee J (1997) Biological conversion of lignocellulosic biomass to ethanol. J. Biotechnol. 56: 1-24

Leonowicz A, Matuszewska A, Luterek J, Ziegenhagen D, Wojtas-Wasilewska M, Cho NS, Hofrichter M \& Rogalski J (1999) Biodegradation of lignin by white rot fungi. Fungal Genet. Biol. 27: 175-185

Leschine SB (1995) Cellulose degradation in anaerobic environments. Annu. Rev. Microbiol. 49: 399-426

Levine JS (1996) Biomass burning and global change. Volume 1. Remote sensing and inventory development, and biomass burning in Africa. In: Levine JS (Ed) (p 35). The MIT Press, Cambridge, Massachusetts, USA

Lonsane BK, Ghildyal NP, Budiatman S \& Ramakrishna SV (1985) Engineering aspects of solid state fermentation. Enzyme Microb. Technol. 7: $258-265$

Lonsane BK, Saucedo-Castaneda G, Raimbault M, Roussos S, Viniegra-Gonzalez G, Ghildyal NP, Ramakrishna M \& Krish-naiah MM (1992) Scale-up strategies for solid state fermentation systems. Process Biochem. 27: 259-273

McCarthy AJ (1987) Lignocellulose-degrading actinomycetes. FEMS Microbiol. Rev. 46: 145-163

McDonald P (1981) The Biochemistry of Silage. John Wiley \& Sons, Chichester, UK, pp 11-12, 168-178

Milstein O, Vered Y, Gressel J \& Flowers HM (1981) Biodegra-dation of wheat straw lignocarbohydrate complexes (LCC) II. Fungal growth on aqueous hydrolysate liquors and particulate residues of wheat straw. Eur. J. Appl. Microbiol. Biotechnol. 13: 117-127

Mitchell WJ (1998) Physiology of carbohydrate to solvent conversion by clostridia. Adv. Microb. Physiol. 39: 31-130

Mudgett RE (1986) Solid-state fermentations. In: Demain AL \& Solomon NA (Eds) Manual of Industrial Microbiology and Biotechnology (pp 66-83). American Society of Microbiology, Washington D.C., USA

Mueller-Harvey I \& Hartley RD (1986) Linkage of p-coumaroyl and feruloyl groups to cell-wall polysaccharides of barley straw. Carbohydrate. Res. 148: 71-85

Paul EA \& Clark FE (1989) Soil Microbiology and Biochemistry. Academic Press, Inc. San Diego, USA

Palmqvist E \& Hahn-Hägerdal B (2000) Fermentation of ligno-cellulosic hydrolysates. I: inhibition and detoxification. Biores. Technol. 74: $17-24$

Rayner ADM \& Boddy L (1988) Fungal communities in the decay of wood. Adv. Microb. Ecol. 10: 115-166

Reid ID (1989) Solid-state fermentations for biological delignifica-tion. Enzyme. Microb. Technol. 11: 786-802

Reid ID (1995) Biodegradation of lignin. Can. J. Bot. 73(Suppl 1): S1011-S1018

Sakagami H, Satoh K, Ida Y, Koyama N, Premanathan M, Arakaki R, Nakashima H, Hatano T, Okuda T \& Yoshida T (1999) Induction of apoptosis and anti-HIV activity by tannin- and lignin-related substances. Basic Life Sci. 66: 595-611

Sarikaya A \& Ladisch MR (1997) Mechanism and potential applications of bio-ligninolytic systems in a CELSS. Appl. Biochem. Biotechnol. 62: $131-149$

Scott GM, Akhtar M, Lentz MJ, Kirk TK \& Swaney R (1998) New technology for papermaking: commercializing biopulping. Tappi J. 81: 220225

Sun RC, Lawther JM \& Banks WB (1996) The fractional composition of polysaccharides and lignin in alkaline pre-treated and steam pressure treated wheat straw. Cellulose Chem. Technol. 30: 57-69

Tomme P, Warren RA \& Gilkes NR (1995) Cellulose hydrolysis by bacteria and fungi. Adv. Microb. Physiol. 37: 1-81

Trigo C \& Ball AS (1994) Is the solubilized product from the degradation of lignocellulose by actinomycetes a precursor of humic substances? Microbiology 140: 3145-3152

Tuor U, Winterhaler K \& Fiechter A (1995) Enzymes of white-rot fungi involved in lignin degradation and ecological determinants for wood decay. J. Biotechnol. 41: 1-17

Van Veen JA, Ladd JN \& Frissel MJ (1984) Modelling C\&N turnover through the microbial biomass in soil. Plant Soil 76: 257-274

Varga GA \& Kolver ES (1997) Microbial and animal limitations to fiber digestion and utilization' J. Nutr. 127: 819S-823S

Vered Y, Milstein O, Flowers HM \& Gressel J (1981) Biodegradation of wheat straw lignocarbohydrate complexes (LCC). I. Dynamics of liberation of hot aqueous LCCs from wheat straw and partial characterization of the products. Eur. J. Appl. Micro-biol. Biotechnol. 12: 183188

Vicuna R (2000) Ligninolysis. A very peculiar microbial process. Mol. Biotechnol. 14: 173-176

Vicuna R, Gonzalez B, Seelenfreund D, Ruttimann C \& Salas L (1993) Ability of natural bacterial isolates to metabolize high and low molecular weight lignin-derived molecules. J. Biotechnol. 30: 9-13

Waldrop MP, Balser TC \& Firestone MK (2000) Linking microbial community composition to function in a tropical soil. Soil Biol. Biochem. 32: $1837-1846$

Wheals AE, Basso LC, Alves DMG \& Amorim HV (1999) Fuel ethanol after 25 years. TIBTECH 17: 482-487

White GF, Russell NJ \& Tidswell EC (1996) Bacterial scission of ether bonds. Microbiol. Rev. 60: 216-232

Wignarajah K, Pisharody S \& Fisher JW (2000) Can incineration technology convert CELSS wastes to resources for crop production? A working hypothesis and some preliminary findings. Adv. Space Res. 26: 327-333

Wilson JR \& Mertens DR (1995) Cell wall accessibility and cell structure limitations to microbial digestion of forage. Crop Sci. 35: 251-259

Wolfaardt JF, Jacobs A, Rabie CJ, Smit S, Taljaardt JL \& Wing-field MJ (1999) Factors affecting colonization of freshly chipped softwood by white-rot fungi. Poster presented at an International Energy Agency Bioenergy Workshop on the Bioconversion of Lignocellulose, Itala Game Reserve, South Africa, 22-26 August

Wubah DA, Akin DE \& Borneman WS (1993) Biology, fiber-degradation, and enzymology of anaerobic zoosporic fungi. Crit. Rev. Microbiol. 19: 99-115

Zadrazil F \& Isikhuemhen O (1997) Solid state fermentation of lignocellulosics into animal feed with white rot fungi. In: Roussos S, Lonsane BK, Raimbault M \& Viniegra-Gonzalez G (Eds) Advances in Solid State Fermentation (pp 23-38). Kluwer Academic Publishers, Dordrecht, The Netherlands 